\title{
Identification of and a Prediction Model for Cognitive Trajectories in Patients With Mild Cognitive Impairment Due to Alzheimer's Disease
}

\section{Sang Won Seo ( $\nabla$ sw72.seo@samsung.com )}

samsung medical center

\section{Seung Joo Kim}

Gyeongsang National University Hospital

\section{Sook-Young Woo}

Samsung Medical Center

Young Ju Kim

Samsung Medical Center

Yeshin Kim

Kangwon National University Hospital

\section{Hyemin Jang}

Samsung Medical Center

\section{Si Eun Kim}

Inje University Busan Paik Hospital

Jun Pyo Kim

Indiana University School of Medicine

\section{Young Hee Jung}

Myongji Hospital

\section{Eun-Joo Kim}

Pusan National University Hospital

Hee Jin Kim

Samsung Medical Center

Duk L. Na

Samsung Medical Center

\section{Seonwoo Kim}

Samsung Medical Center

\section{Research}

Keywords: Mild cognitive impairment, Amyloid, Alzheimer's disease, cognition, trajectory, prediction

Posted Date: December 30th, 2020

DOI: https://doi.org/10.21203/rs.3.rs-135650/v1

License: (9) (i) This work is licensed under a Creative Commons Attribution 4.0 International License. Read Full License 


\section{Abstract}

Background: Few studies have investigated cognitive trajectories or developed a prediction model for amyloid beta-positive $(A \beta+)$ mild cognitive impairment $(\mathrm{MCl})$ patients. We aimed to identify distinct cognitive trajectories in $\mathrm{A} \beta+\mathrm{MCl}$ patients based on longitudinal Alzheimer's Disease Assessment Scale-Cognitive subscale (ADAS-cog) 13 scores. Furthermore, we aimed to develop and visualize a prediction model to predict trajectory groups using the demographic, genetic, and clinical biomarkers of $\mathrm{A} \beta+\mathrm{MCl}$ patients.

Methods: We performed a retrospective analysis of the data in $238 \mathrm{~A} \beta+\mathrm{MCl}$ patients from the Alzheimer's Disease Neuroimaging Initiative who underwent at least three rounds of annual neuropsychological testing to identify cognitive trajectories. A group-based trajectory model (GBTM) was used to classify distinct groups based on ADAS-cog 13 scores. The prediction model was estimated using multinomial logistic regression and visualized using a bar-based method for risk prediction.

Results: Three distinct classes, namely slow decliners (18.5\%), intermediate decliners (42.9\%), and fast decliners (38.7\%), were suggested. Intermediate decliners were associated with higher age ( $\geq 70$ years) (odds ratio [OR] 2.72, 95\% confidence interval [CI] 1.78-6.28), higher AV45 standardized uptake value ratios (SUVRs)*10 (OR 1.69, 95\% Cl 1.22-2.34), and lower fluorodeoxyglucose (FDG) SUVR*10 (OR 0.65, 95\% Cl 0.46-0.93) than slow decliners. Fast decliners were associated with higher age ( $\geq 70$ years) (OR 3.76, 95\% Cl 1.40-10.10), greater likelihood of being an apolipoprotein $\mathrm{E} 4$ carrier $(\mathrm{OR} 4.2,95 \% \mathrm{Cl}$ 1.53-11.58), higher AV45 positron emission tomography SUVR ${ }^{\star} 10$ (OR 2.14, 95\% Cl 1.50-3.05), and lower FDG SUVR 10 (OR $0.31,95 \% \mathrm{Cl} 0.20-0.48)$ than slow decliners. The predicted probability of being classified to a trajectory group according to the risk scores of predictors was visualized.

Conclusions: Our GBTM analysis yielded novel insights into the heterogeneous cognitive trajectories among $A \beta+\mathrm{MCl}$ patients, which further facilitates the effective stratification of $A \beta+\mathrm{MCl}$ patients in $A \beta$-targeted clinical trials.

\section{Introduction}

Mild cognitive impairment $(\mathrm{MCl})$ is a heterogeneous syndrome that is thought to be a transition phase between normal cognition and dementia [1-3]. Recent advances in molecular and imaging markers have allowed the detection of the presence of amyloid-beta $(A \beta)$ deposition as a landmark of Alzheimer's disease $(A D)$ in patients with $M C I[4,5]$. $A \beta$ is an increasingly common target of potential disease-modifying drug development. In addition, $\mathrm{MCl}$ as an appropriate early stage disease marker has been considered to improve the efficacy of treatment.

$\mathrm{MCl}$ patients' clinical outcomes are heterogeneous and the rate of cognitive decline varies among patients $[3,6,7]$. In particular, although $\mathrm{MCl}$ patients with $\mathrm{A} \beta$-positive $(\mathrm{A} \beta+)$ positron emission tomography $(\mathrm{PET})$ findings are more likely to progress to dementia than their $A \beta$-negative counterparts [8-11], $A \beta+\mathrm{MCl}$ patients have different prognoses according to their downstream biomarker status, such as the cerebrospinal fluid (CSF) tau level, hippocampal atrophy, and hypometabolism [1214]. This may result from the interaction of underlying pathologies and multiple factors, such as genetics and comorbidities [15-17]. Indeed, previous studies have shown that $A \beta+\mathrm{MCl}$ patients can be classified into converters and non-converters within 3 years $[8,18]$. Therefore, determining the stratified disease prognosis even among $A \beta+\mathrm{MCl}$ patients is clinically essential. The early prediction of individuals at risk of rapidly developing dementia due to $A D$ among $A \beta+\mathrm{MCl}$ patients could have major implications for early treatment and clinical trials.

The group-based trajectory analysis model (GBTM) is a tool for analyzing developmental trajectories and provides an estimated proportion of each subgroup following the same latent trajectory among a mixture of distinct groups [19, 20]. Groupbased models have been applied to identify developmental trajectories among patients with amnestic and non-amnestic $\mathrm{MCl}$ [21-23], but this method has not yet been utilized to determine longitudinal cognitive trajectories among $A \beta+\mathrm{MCl}$ patients. However, predictive models of AD dementia have been generated using pattern classification methods based on clinical, 
imaging, and CSF biomarkers $[18,24,25]$. A risk prediction model for disease progression is important for clinical trials as well as guiding clinical decision-making and early treatment.

Here, we aimed to identify distinct cognitive trajectories in $A \beta+\mathrm{MCl}$ patients and to develop a model for predicting trajectory groups using potential predictive factors.

\section{Methods}

\section{Participants}

Data were drawn from the Alzheimer's Disease Neuroimaging Initiative (ADNI) database (http://adni.loni.usc.edu), including ADNI-1, ADNI-GO, and ADNI-2. MCl participants with subjective memory complaints, a Mini-Mental State Examination score of 23-30, and a Clinical Dementia Rating score of 0.5 were included [26]. $\mathrm{MCl}$ participants comprised both early $\mathrm{MCl}$ and late $\mathrm{MCl}$ patients, who were categorized using the Wechsler Memory Scale Logical Memory II; early MCl is indicated by a score of 0.51.5 standard deviations (SDs) below the mean of Cognitively Normal on delayed recall and late $\mathrm{MCl}$ refers to a score of $>1.5$ SDs below the normative mean $[18,27]$.

In this study, we selected 238 patients with $\mathrm{MCl}$ from the ADNI-GO and ADNI-2 who were A + , which we defined as a standardized uptake value ratio (SUVR) of $>1.11$ at baseline $[28,29]$. After the baseline visit, the patients were followed-up at 6 or 12-month intervals for clinical and standardized neuropsychological assessments including the Alzheimer's Disease Assessment Scale-Cognitive subscale (ADAS-cog) 13 questionnaire, brain imaging (fluorodeoxyglucose [FDG] PET, and 18FAV45 [Florbetapir] PET), and apolipoprotein E (APOE) genotyping at least three times throughout the study period.

\section{Collection of clinical and multimodal biomarkers}

Clinical data including demographic information, neuropsychological scores, and APOE genotype were acquired from the ADNIMERGE dataset from the ADNI database (http://adni.loni.usc.edu). The ADAS-cog 13 score, with higher scores reflecting cognitive decline [30] was used as a dependent measure for our longitudinal analyses. Additionally, we collected the average FDG and AV45 SUVRs of AD signature regions [31]. The detailed imaging standardized protocols have been described previously $[29,32,33]$.

\section{Statistical analysis}

To discover distinct trajectories based on the longitudinal ADAS-Cog 13 scores and develop a visualized risk prediction model for trajectory groups, we carried out the following four steps: 1) classifying distinct trajectory groups according to longitudinal ADAS-Cog 13 scores, 2) comparing demographic/clinical variables among classified trajectory groups, 3) constructing a model for predicting the trajectory groups, and 4) visualizing the prediction model. First, GBTM was used to group individuals into the number of distinct clusters represented by the progression of ADAS-cog 13 score trajectories over time in such a manner that individuals in the same group had more similar trajectories to one another than to those in other groups. The ADAS-Cog 13 scores were natural log transformed after adding 2 to all scores due to non-normality. The fitness of GBTM i.e., the number of trajectory groups and the linearity or nonlinearity (quadratic or cubic) of the model was evaluated using the Bayesian information criterion (BIC) and sample size-adjusted BIC (SABIC) $[20,34,35]$. To investigate the stability of the trajectory groups identified, the bootstrap procedure with 1,000 samples was employed [36, 37]. GBTM was applied to each bootstrap sample, and the difference between the estimates of each parameter from the original sample and the bootstrap sample and 95\% confidence interval $(\mathrm{Cl})$ of the difference were calculated. Second, the demographic and clinical variables among the trajectory groups were compared using the Kruskal Wallis test due to non-normality of continuous variables. Categorical variables were compared using the Chi-squared test. For multiple comparison analysis, Tukey's test using ranks for continuous variables or Fisher's exact test with the permutation method for categorical variables was performed. Third, the prediction model for the trajectory groups was estimated using a multinomial logistic model. Odds ratios (ORs) and $95 \%$ Cls of ORs with this model were estimated to assess the size of the association between predictors and trajectory groups. Linearity for continuous variables in the model was investigated using a plot of log odds. Continuous variables that did not meet the 
linearity were categorized into two groups (age: $<70$ years, $\geq 70$ years; education: $<12$ years and $\geq 12$ years) [38]. FDG and 18FAV45 SUVR were multiplied by 10 because of the relatively small scale. Prediction model estimation was performed using a hierarchical procedure, and the variable was included in the model in the order of variables that are easy to use in the clinic. We evaluated the fitness and predictability of each estimated model using the Akaike information criterion (AIC), Schwarz Criterion (SC), R-square, M-index [39], and polytomous discrimination index (PDI) [40] and compared the goodness of fit of competing models using the likelihood ratio test. In order to display the risk score of predictors and the predicted probability of belonging to a trajectory group given a specific patient's predictors, we used bar-based representation [38]. The bar representing each predictor corresponded to a risk score. The patient's score was the sum of the risk scores for all predictors. This total score was converted into a predicted probability, which was a trajectory group.

Continuous and categorical variables are summarized as the median (interquartile range [IQR], 1st -3rd quartile), and frequency (percentage), respectively. Statistical analyses were performed using SAS 9.4 (SAS Institute Inc., United States) and the PROC TRAJ macro (http://www.andrew.cmu.edu/user/bjones) [41, 42]. The 'VRPM' package in R 3.6.1 (Vienna, Austria; http://www.Rproject.org/) was also used. A two-sided $p$ value $<0.05$ was considered to indicate statistical significance.

\section{Results}

\section{Demographics of study participants}

The detailed demographics and clinical characteristics of the 238 subjects are presented in Table 1. The median age of the study subjects was 73.2 years (IQR, 68.3-77.6 years). The median duration of education was 16 years (IQR, 14-18 years). Female patients accounted for $44.1 \%$ and the frequency of APOE $\varepsilon 4$ carriers was $67.7 \%$. 
Table 1

Demographics and clinical characteristics among three classified groups based on cognitive trajectory analysis

\begin{tabular}{|c|c|c|c|c|c|c|c|c|}
\hline & Total & $\begin{array}{l}\text { Slow } \\
\text { decliners }\end{array}$ & $\begin{array}{l}\text { Intermediate } \\
\text { decliners }\end{array}$ & $\begin{array}{l}\text { Fast } \\
\text { decliners }\end{array}$ & \multirow[t]{2}{*}{$\begin{array}{l}p \\
\text { value* }\end{array}$} & \multirow[t]{2}{*}{$\begin{array}{l}\text { Slow vs. } \\
\text { Intermediate } \\
p \text { value }\end{array}$} & \multirow{2}{*}{$\begin{array}{l}\text { Slow } \\
\text { vs. } \\
\text { Fast } \\
p \\
\text { value }\end{array}$} & \multirow[t]{2}{*}{$\begin{array}{l}\text { Intermediate } \\
\text { vs. Fast } \\
p \text { value }\end{array}$} \\
\hline & $\begin{array}{l}(n= \\
238)\end{array}$ & $(n=44)$ & $(n=102)$ & $(n=92)$ & & & & \\
\hline \multicolumn{9}{|l|}{ Demographics } \\
\hline $\begin{array}{l}\text { Age, median } \\
\text { (IQR), years }\end{array}$ & $\begin{array}{l}73.2 \\
(68.3- \\
77.6)\end{array}$ & $\begin{array}{l}68.4 \\
(65.3- \\
72.5)\end{array}$ & $\begin{array}{l}75.2(68.9- \\
79.3)\end{array}$ & $\begin{array}{l}74.0 \\
(69.7- \\
77.5)\end{array}$ & $\begin{array}{l}<.001^{\mathrm{a}} \\
\end{array}$ & $<0.001^{c}$ & $0.001^{c}$ & $0.692^{c}$ \\
\hline $\begin{array}{l}\text { Age } \geq 70 \text { years, } n \\
(\%)\end{array}$ & $\begin{array}{l}155 \\
(65.4)\end{array}$ & $\begin{array}{l}17 \\
(38.64)\end{array}$ & $70(69.31)$ & $\begin{array}{l}68 \\
(73.91)\end{array}$ & $\begin{array}{l}< \\
0.001^{b}\end{array}$ & $0.002^{d}$ & $\begin{array}{l}< \\
0.001^{d}\end{array}$ & $0.729^{d}$ \\
\hline Female sex, n (\%) & $\begin{array}{l}105 \\
(44.1)\end{array}$ & $\begin{array}{l}23 \\
(52.27)\end{array}$ & $43(42.16)$ & $\begin{array}{l}39 \\
(42.39)\end{array}$ & $\begin{array}{l}0.483 \\
b\end{array}$ & $0.503^{d}$ & $0.56^{d}$ & $1^{d}$ \\
\hline $\begin{array}{l}\text { Education, } \\
\text { median (IQR), } \\
\text { years }\end{array}$ & $\begin{array}{l}16(14- \\
18)\end{array}$ & $\begin{array}{l}17(16- \\
19.5)\end{array}$ & $16(13-18)$ & $\begin{array}{l}16(14- \\
18)\end{array}$ & $\begin{array}{l}0.027 \\
a\end{array}$ & $0.022^{c}$ & $0.321^{c}$ & $0.289^{c}$ \\
\hline $\begin{array}{l}\text { Education > } 12 \\
\text { years, n (\%) }\end{array}$ & $\begin{array}{l}196 \\
(82.7)\end{array}$ & $41(93.2)$ & $79(78.2)$ & $\begin{array}{l}76 \\
(82.6)\end{array}$ & $0.091^{b}$ & $0.059^{d}$ & $0.2^{d}$ & $0.69^{d}$ \\
\hline \multicolumn{9}{|l|}{ Biomarkers } \\
\hline $\begin{array}{l}\text { APOE } \varepsilon 4 \text { carriers, } \\
\text { n (\%) }\end{array}$ & $\begin{array}{l}161 \\
(67.7)\end{array}$ & $\begin{array}{l}24 \\
(54.55)\end{array}$ & $62(60.78)$ & $\begin{array}{l}75 \\
(81.52)\end{array}$ & $\begin{array}{l}0.001 \\
b\end{array}$ & $0.828^{d}$ & $0.003^{d}$ & $0.003^{d}$ \\
\hline $\begin{array}{l}\text { AV45 PET SUVR, } \\
\text { median (IQR) }\end{array}$ & $\begin{array}{l}1.3 \\
(1.2- \\
1.5)\end{array}$ & $\begin{array}{l}1.2( \\
1.2-1.3)\end{array}$ & $\begin{array}{l}1.4(1.2- \\
1.5)\end{array}$ & $\begin{array}{l}1.4 \\
(1.3- \\
1.5)\end{array}$ & $\begin{array}{l}< \\
0.001 \\
a\end{array}$ & $<0.001^{c}$ & $\begin{array}{l}< \\
0.001^{c}\end{array}$ & $0.003^{c}$ \\
\hline FDG PET SUVR, & $\begin{array}{l}1.2 \\
(1.1- \\
1.3)\end{array}$ & $\begin{array}{l}1.4(1.3- \\
1.4)\end{array}$ & $\begin{array}{l}1.3(1.2- \\
1.3)^{(-1}\end{array}$ & $\begin{array}{l}1.2 \\
(1.1- \\
1.2)\end{array}$ & $\begin{array}{l}< \\
0.001 \\
a\end{array}$ & $0.001^{c}$ & $\begin{array}{l}< \\
0.001^{c}\end{array}$ & $<0.001^{c}$ \\
\hline \multicolumn{9}{|l|}{ median (IQR) } \\
\hline $\begin{array}{l}\text { ADAS-cog } \\
\text { (Baseline), } \\
\text { median (IQR) }\end{array}$ & \multicolumn{8}{|l|}{$\begin{array}{l}16(12- \\
21)\end{array}$} \\
\hline \multicolumn{9}{|c|}{$\begin{array}{l}\text { Abbreviations: } \mathrm{MCl} \text { mild cognitive impairment; APOE, apolipoprotein E; SUVR, standardized uptake value ratio; FDG, } \\
\text { fluorodeoxyglucose; ADAS-cog, Alzheimer's Disease Assessment Scale-Cognitive subscale; PET, positron emission } \\
\text { tomography; IQR, interquartile range }\end{array}$} \\
\hline \multicolumn{9}{|c|}{ *Overall comparison for the three trajectory groups } \\
\hline \multicolumn{9}{|c|}{ a: Kruskal-Wallis test } \\
\hline \multicolumn{9}{|l|}{ b: Chi-square test } \\
\hline \multicolumn{9}{|c|}{ c: Tukey test using ranks } \\
\hline d: Fisher's exact te & ith per & on met & r multiple & & & & & \\
\hline
\end{tabular}


Table 2

Comparison of parameters for the group based trajectory model between the original sample and the bootstrap sample

\begin{tabular}{|c|c|c|c|c|c|c|c|c|}
\hline \multirow[t]{2}{*}{ Group } & \multirow[t]{2}{*}{ Parameter } & \multicolumn{3}{|c|}{ Original sample } & \multicolumn{3}{|c|}{ Bootstrap sample } & \multirow{2}{*}{$\begin{array}{l}\text { delta of } \\
\text { betat ( } 95 \% \\
\text { Cl) }\end{array}$} \\
\hline & & Beta (SE) & $\begin{array}{l}\% \\
\text { Sample }\end{array}$ & $\begin{array}{l}\text { Posterior } \\
\text { probability* }\end{array}$ & Beta (SE) & $\begin{array}{l}\% \\
\text { Sample }\end{array}$ & $\begin{array}{l}\text { Posterior } \\
\text { probability* }\end{array}$ & \\
\hline \multirow[t]{3}{*}{$\begin{array}{l}\text { Slow } \\
\text { decliners }\end{array}$} & Intercept & $2.3(0.03)$ & 18.49 & $0.19(0.38)$ & $2.29(0.01)$ & 18.58 & $0.19(0.38)$ & $\begin{array}{l}0.007 \\
(-0.063- \\
0.076)\end{array}$ \\
\hline & Linear & $\begin{array}{l}-0.01 \\
(0.003)\end{array}$ & & & $\begin{array}{l}-0.01 \\
(0.0004)\end{array}$ & & & $\begin{array}{l}0.000316 \\
(-0.005- \\
0.005)\end{array}$ \\
\hline & Quadratic & $\begin{array}{l}0.0003 \\
(0.00004)\end{array}$ & & & $\begin{array}{l}0.0003 \\
(0.000008)\end{array}$ & & & $\begin{array}{l}0 \\
(-0.00008- \\
0.000079)\end{array}$ \\
\hline \multirow[t]{3}{*}{$\begin{array}{l}\text { Intermediate } \\
\text { decliners }\end{array}$} & Intercept & $\begin{array}{l}2.79 \\
(0.02)\end{array}$ & 42.86 & $0.42(0.46)$ & $\begin{array}{l}2.78 \\
(0.004)\end{array}$ & 42.5 & $0.42(0.46)$ & $\begin{array}{l}0.003 \\
(-0.045- \\
0.05)\end{array}$ \\
\hline & Linear & $\begin{array}{l}-0.001 \\
(0.002)\end{array}$ & & & $\begin{array}{l}-0.001 \\
(0.0002)\end{array}$ & & & $\begin{array}{l}0(-0.004- \\
0.004)\end{array}$ \\
\hline & Quadratic & $\begin{array}{l}0.0001 \\
(0.00003)\end{array}$ & & & $\begin{array}{l}0.0001 \\
(0.000002)\end{array}$ & & & $\begin{array}{l}0 \\
(-0.00005- \\
0.00006)\end{array}$ \\
\hline \multirow[t]{2}{*}{$\begin{array}{l}\text { Fast } \\
\text { decliners }\end{array}$} & Intercept & $\begin{array}{l}3.17 \\
(0.02)\end{array}$ & 38.66 & $0.40(0.46)$ & $\begin{array}{l}3.17 \\
(0.003)\end{array}$ & 38.93 & $0.40(0.46)$ & $\begin{array}{l}0.001 \\
(-0.039- \\
0.042)\end{array}$ \\
\hline & Linear & $\begin{array}{l}0.01 \\
(0.001)\end{array}$ & & & $\begin{array}{l}0.01 \\
(0.0001)\end{array}$ & & & $\begin{array}{l}0 \\
(-0.00142- \\
0.00147)\end{array}$ \\
\hline \multicolumn{9}{|c|}{ Abbreviations: $\mathrm{Cl}$, Confidence interval; SE, Standard error } \\
\hline \multicolumn{9}{|c|}{ *Reported as average posterior probability (standard deviation) } \\
\hline
\end{tabular}

\section{Classifying distinct trajectory groups for longitudinal ADAS-Cog 13 scores}

We identified three trajectory groups, two of which had quadratic trajectories and one of which had a linear trajectory (Fig. 1) $(\mathrm{BIC}=840.87, \mathrm{SABIC}=797.16)$. As shown in Fig. 1, we obtained three distinct groups: slow decliners, intermediate decliners, and fast decliners. Quadratic patterns for the 44 slow decliners (18.5\%) and 102 intermediate decliners (42.9\%) and a linear pattern for 92 fast decliners (38.7\%) appeared (Fig. 1). The parameter estimates of the model, the proportion of individuals assigned to each trajectory group, and posterior probability were very similar between the original sample and bootstrap sample, suggesting the stability of the trajectory groups identified in the original sample (Table 2).

\section{Comparisons of clinical characteristics among the distinct trajectory groups}

The median age was the lowest in the slow decliner group (Tukey's test using ranks: slow vs. intermediate $p<0.001$; slow vs. fast $p=0.001$; intermediate vs. fast $p=0.692$ ). The sex distribution did not significantly differ (Chi-square test; $p=0.483$ ) among the three groups, but years of education was higher in the slow decliner group than in the intermediate decliner group 
(Tukey's test using ranks: slow vs. intermediate $p=0.022$; slow vs. fast $p=0.321$; intermediate vs. fast $p=0.289$ ). The presence of APOE $\varepsilon 4$ was more common among fast decliners than among slow and intermediate decliners (Fisher's exact test with permutation method for multiple testing: slow vs. intermediate $p=0.828$; slow vs. fast $p=0.003$; intermediate vs. fast $p=$ 0.003). In a comparison of biomarkers including PET SUVR, all factors significantly differed among the three groups. The median AV45 PET SUVR was lower in the slow decliner group than in the other two groups (Tukey's test using ranks: slow vs. intermediate $p<0.001$; slow vs. fast $p<0.001$; intermediate vs. fast $p=0.003$ ). In addition, the median FDG PET SUVR was lower in the fast decliner group than in the other two groups (Tukey's test using ranks: slow vs. intermediate $p=0.001$; slow vs. fast $p<0.001$; intermediate vs. fast $p<0.001$ ).

\section{Development of the prediction model}

Each model was estimated by adding variables in the order of demographic variables, APOE $\varepsilon 4$ status, and variables related to PET SUVR. Table 3 shows the fitness and predictability indices of the models and the results of the comparison test for goodness of fit between models. The model with age, APOE $\varepsilon 4$, FDG PET SUVR, AV45 PET SUVR, and education (Model 5) and the model with age, APOE $\varepsilon 4$, FDG PET SUVR, and AV45 PET SUVR (Model 6) provided a lower AIC, lower SC, higher R-square, higher $\mathrm{M}$ index, and higher PDI, indicating that these two models were superior to the other models. Models 5 and 6 exhibited similar performances for fitness and predictability and no significant differences in terms of goodness of fit (likelihood ratio test; $p=0.183$ ), but Model 6 was selected as the final model due to the relatively lower number of predictive factors. In the final model, intermediate decliners were associated with higher age ( $\geq 70$ years) (OR 2.72, 95\% Cl 1.78-6.28), higher AV45 PET SUVR*10 (OR 1.69, 95\% Cl 1.22-2.34), and lower FDG PET SUVR*10 (OR 0.65, 95\% Cl 0.46-0.93) but not a higher proportion of APOE $\varepsilon 4$ carriers $(\mathrm{OR} 1.53,95 \% \mathrm{Cl} 0.66,3.54)$ than slow decliners. Fast decliners were associated with higher age $(\geq$ 70 years) (OR 3.76, 95\% $\mathrm{Cl} 1.40-10.10$ ), higher proportion of APOE $\varepsilon 4$ carriers (OR 4.2, 95\% $\mathrm{Cl} 1.53-11.58$ ), higher AV45 PET SUVR ${ }^{*} 10$ (OR 2.14, 95\% Cl 1.50-3.05), and lower FDG PET SUVR*10 (OR 0.31, 95\% Cl 0.20-0.48) than slow decliners (Table 4). 
Table 3

Comparisons of models with different combinations of predictors

\begin{tabular}{|c|c|c|c|c|c|c|c|c|c|c|c|}
\hline & \multirow[t]{2}{*}{ AIC } & \multirow[t]{2}{*}{ SC } & \multirow{2}{*}{$\begin{array}{l}\text { R-Square } \\
\text { (Nagelkerke) }\end{array}$} & \multirow[t]{2}{*}{$\begin{array}{l}\text { M- } \\
\text { index }\end{array}$} & \multicolumn{2}{|c|}{$\begin{array}{l}95 \% \mathrm{Cl}^{\star} \text { for } \mathrm{M} \\
\text { index }\end{array}$} & \multirow[t]{2}{*}{ PDI } & \multicolumn{4}{|c|}{ Likelihood ratio Test } \\
\hline & & & & & Lower & Upper & & $\begin{array}{l}\text { Model } \\
\text { comparison }\end{array}$ & $\begin{array}{l}\text { Chi- } \\
\text { squared } \\
\text { value }\end{array}$ & DF & $p$ value \\
\hline $\begin{array}{l}\text { Model } \\
1\end{array}$ & 485.47 & 506.28 & 0.10 & 0.63 & 0.57 & 0.68 & 0.27 & - & - & - & - \\
\hline $\begin{array}{l}\text { Model } \\
2\end{array}$ & 472.00 & 499.75 & 0.17 & 0.67 & 0.6 & 0.72 & 0.43 & $\begin{array}{l}\text { Model } 1 \text { vs. } \\
\text { Model } 2\end{array}$ & 17.47 & 2 & 0.0002 \\
\hline $\begin{array}{l}\text { Model } \\
3\end{array}$ & 416.76 & 451.44 & 0.39 & 0.78 & 0.72 & 0.83 & 0.66 & $\begin{array}{l}\text { Model } 2 \text { vs. } \\
\text { Model } 3\end{array}$ & 59.25 & 2 & $<0.0001$ \\
\hline $\begin{array}{l}\text { Model } \\
4\end{array}$ & 439.59 & 474.27 & 0.31 & 0.75 & 0.65 & 0.78 & 0.61 & $\begin{array}{l}\text { Model } 2 \text { vs. } \\
\text { Model } 4\end{array}$ & 36.41 & 2 & $<0.0001$ \\
\hline \multirow[t]{2}{*}{$\begin{array}{l}\text { Model } \\
5\end{array}$} & 398.74 & 440.36 & 0.45 & 0.81 & 0.74 & 0.85 & 0.70 & $\begin{array}{l}\text { Model } 3 \text { vs. } \\
\text { Model } 5\end{array}$ & 22.01 & 2 & $<0.0001$ \\
\hline & & & & & & & & $\begin{array}{l}\text { Model } 4 \text { vs. } \\
\text { Model } 5\end{array}$ & 44.84 & 2 & $<0.0001$ \\
\hline $\begin{array}{l}\text { Model } \\
6\end{array}$ & 398.16 & 432.84 & 0.44 & 0.81 & 0.73 & 0.85 & 0.69 & $\begin{array}{l}\text { Model } 5 \text { vs. } \\
\text { Model } 6\end{array}$ & 3.41 & 2 & 0.1813 \\
\hline \multicolumn{12}{|c|}{ Model 1: age, education } \\
\hline \multicolumn{12}{|c|}{ Model 2: age, education, APOE $\varepsilon 4$ (carrier, non-carrier) } \\
\hline \multicolumn{12}{|c|}{ Model 3: age, education, APOE $\varepsilon 4$, FDG PET SUVR } \\
\hline \multicolumn{12}{|c|}{ Model 4: age, education, APOE $\varepsilon 4$, AV45 PET SUVR } \\
\hline \multicolumn{12}{|c|}{ Model 5: age, education, APOE ع4, FDG PET SUVR, AV45 PET SUVR } \\
\hline \multicolumn{12}{|c|}{ Model 6: age, APOE4, FDG PET SUVR, AV45 PET SUVR } \\
\hline \multicolumn{12}{|c|}{$\begin{array}{l}\text { Abbreviations: APOE, apolipoprotein E; PET, positron emission tomography; SUVR, standardized uptake value ratio; FDG, } \\
\text { fluorodeoxyglucose; AIC, Akaike information criterion; SC, Schwarz criterion; M index, multiclass area under receiver } \\
\text { operating characteristic index; PDI, polytomous discrimination index; DF, degrees of freedom }\end{array}$} \\
\hline
\end{tabular}


Table 4

Multinominal logistic regression of predictors for the three trajectory groups of amyloid-positive mild cognitive impairment patients

\begin{tabular}{|llllllll|}
\hline & \multicolumn{2}{l}{ Intermediate decliners* } & \multicolumn{2}{ll}{ Fast decliners* } \\
\hline & OR & $95 \% \mathrm{Cl}$ & $p$ value & OR & $95 \% \mathrm{Cl}$ & $p$ value \\
\hline Age, $(\geq 70$ years $)$ & 2.72 & $1.78,6.28$ & 0.002 & 3.76 & $1.40,10.10$ & $<0.001$ \\
\hline Presence of APOE $\varepsilon 4$ & 1.53 & $0.66,3.54$ & 0.158 & 4.20 & $1.53,11.58$ & $<0.001$ \\
\hline AV45 PET SUVR * 10 & 1.69 & $1.22,2.34$ & $<0.001$ & 2.14 & $1.50,3.05$ & $<0.001$ \\
\hline FDG PET SUVR * 10 & 0.65 & $0.46,0.93$ & $<0.001$ & 0.31 & $0.20,0.48$ & $<0.001$ \\
\hline
\end{tabular}

Abbreviations: $\mathrm{MCl}$, mild cognitive impairment; OR, odds ratio; $\mathrm{Cl}$, confidence interval; $\mathrm{APOE}$, apolipoprotein E; PET, positron emission tomography; SUVR, standardized uptake value ratio; FDG, fluorodeoxyglucose.

* Slow decliners as reference.

\section{Visualization of the prediction model}

Finally, we visualized the risk score of the predictor and the predicted probability of belonging to a trajectory group using the prediction model given an individual patient's predictors (Fig. 2). Specifically, for a patient aged 75 years, an APOE $\varepsilon 4$ carrier, with an AV45 SUVR of 1.3, and with a FDG SUVR of 1.2, the total score of the intermediate decliner group compared to the slow decliner group and the total score of the fast decliner group compared to the slow decliner group was calculated to be 3.108 and -1.481 , respectively, as shown in Fig. 2. In addition, the predicted probabilities of being in the intermediate and fast decliner groups corresponding to the total scores for this patient were $43.6 \%$ and $50 \%$, respectively. The predicted probability of being in the slow decliner group was $6.4 \%(=100 \%-[43.6 \%+50 \%])$.

\section{Discussion}

In the present study, we investigated several distinct trajectories based on longitudinal measures of cognitive decline using ADAS- $\operatorname{cog} 13$ scores in patients with $\mathrm{MCl}$ due to $\mathrm{AD}$. Our major findings were as follows: 1 ) three distinct groups, slow decliners (18.5\%), intermediate decliners (42.9\%), and fast decliners (38.6\%), were proposed; 2 ) age of $\geq 70$ years, the presence of APOE $\varepsilon 4$, a higher amyloid SUVR, and hypometabolism were predictive of fast decliners; 3 ) a newly developed prediction model may indicate the probability of belonging to each group according to age ( $<70, \geq 70$ years), the presence of APOE $\varepsilon 4$, the AV45 PET SUVR, and the FDG PET SUVR even in the same $A \beta+\mathrm{MCl}$ patient. Taken together, our analysis provides novel insights into the heterogeneous cognitive trajectories among $A \beta+M C l$ patients, which further facilitates the effective stratification of $A \beta+\mathrm{MCl}$ participants in $A \beta$-targeted clinical trials.

Our first major finding was that $\mathrm{A} \beta+\mathrm{MCl}$ patients were classified into three groups based on changes in cognitive performance by trajectory analysis: slow, intermediate, and fast decliners. Previous studies have reported several latent patterns of cognitive change in patients with varying severity of cognitive impairment [21, 43-48]. Our finding was consistent with those of some previous studies showing that individuals with $\mathrm{MCl}$, regardless of the presence or absence of amyloid, had several distinct trajectories of cognitive progression [43-45]. However, unlike previous studies, our study focused on $\mathrm{A} \beta+\mathrm{MCl}$ patients because many clinical trials have recruited $A \beta+\mathrm{MCl}$ patients. In particular, this modeling approach extends beyond recent binary classification approaches that are determined by discretionary criteria regarding the progression from $\mathrm{MCl}$ to dementia within a 3-year period. Furthermore, our study employed a data-driven classification of $A \beta+\mathrm{MCl}$ based on longitudinal cognitive performance, rather than a longitudinal analysis based on a priori classification.

Our second major finding was that older age, the presence of APOE $\varepsilon 4$, a higher amyloid SUVR, and hypometabolism were predictive of fast decline. Previous studies have indicated that older age and hypometabolism are predictive of faster disease 
progression in participants with $\mathrm{MCl}[18,28,38]$. Our notable finding was that greater $A \beta$ deposition predicted a faster decline in $A \beta+\mathrm{MCl}$ patients. Many previous studies have demonstrated that $A \beta$ deposition is reflective of earlier changes in $A D$ and is not correlated with rapid disease progression [49]. However, reduced levels of $A \beta$ in the steady state before cognitive impairment may already be triggered by the deposition of $A \beta$ plaques. Hence, reduced levels of $A \beta$ could be the new "set point" for $A \beta$ at baseline and correlate with disease progression [50]. We also found that the presence of APOE $\varepsilon 4$ in $A \beta+M C l$ patients was associated with more rapid cognitive decline, regardless of $A \beta$ and downstream markers. APOE $\varepsilon 4$ is the strongest genetic risk factor for $A D$ and is consistently associated with abnormal $A \beta$ aggregation and deposition [51]. However, our findings suggest that APOE $\varepsilon 4$ may influence cognitive decline via unknown underlying mechanisms as well as $A \beta$ and downstream marker-related mechanisms in $A \beta+\mathrm{MCl}$ patients. Further studies are needed to replicate our findings in another cohort.

Our final major finding was that a newly developed model could visualize the risk prediction of trajectory groups for individual patients, even in relatively homogenous population of $A \beta+\mathrm{MCl}$ participants. In the present study, we graphically presented both the risk score of each predictor and the total score and provided the predicted probability of belonging to the trajectory group given the observations of predictors for an individual patient. Therefore, the model may easily indicate and more intuitively interpret the results.

\section{Limitations}

This study has several limitations. First, we used basic demographic factors and biomarkers as predictive factors for the trajectory group without considering serial magnetic resonance imaging (MRI) factors and the presence of different underlying diseases such as vascular risk factors. Imaging factors such as brain structural volume and information regarding underlying diseases could improve the performance of the prediction model. Second, to assess A $\beta$ positivity, we used a quantitative SUVR cutoff rather than visual interpretation. However, although visual assessment can be easily used in clinical applications, the SUVR cutoff is more sensitive for predicting the probability of a high risk of progression. Finally, we performed only internal validation using the bootstrap method to validate the predictive accuracy. External validation as an independent validation set is needed to obtain more evidence for the stability of this model. Despite this limitation, our novel prediction model highlights the clinical utility and applicability of risk prediction for disease progression.

\section{Conclusions}

In summary, we developed a model to predict faster decliners among $A \beta+\mathrm{MCI}$ patients using the ADNI dataset. Our model for predicting trajectory groups showed good predictive performance, although we excluded MRI and CSF biomarkers as predicting factors. Additionally, we visualized the risk prediction model for individuals based on extending the conventional trajectory model approach. Thus, our approach has high potential to predict fast decliners among $\mathrm{A} \beta+\mathrm{MCl}$ patients and guide personalized interventions.

\section{Abbreviations}

MCl: Mild cognitive impairment; Aß: Amyloid-beta; AD: Alzheimer's disease; A $\beta+$ : amyloid-beta-positive; PET: Positron emission tomography; CSF: Cerebrospinal fluid; GBTM: Group-based trajectory analysis model; ADNI: Alzheimer's Disease Neuroimaging Initiative; SD: Standard deviation; SUVR: Standardized uptake value ratio; ADAS-cog: Alzheimer's Disease Assessment ScaleCognitive subscale; FDG: Fluorodeoxyglucose; APOE: Apolipoprotein E; BIC: Bayesian information criterion; SABIC: Sample size-adjusted Bayesian information criterion; Cl: Confidence interval; OR: Odds ratio; AIC: Akaike information criterion; SC: Schwarz Criterion; PDI: Polytomous discrimination index; IQR: Interquartile range; SE: Standard error; MRI: Magnetic resonance imaging

\section{Declarations}

\section{Ethics approval and consent to participate}

Page $10 / 15$ 
All procedures performed were in accordance with the ethical standards of the institution and/or national research committee and its later amendments or comparable ethical standards.

\section{Consent for publication}

All patients provided written informed consent as ADNI.

\section{Competing interests}

The authors declare that they have no competing interests.

\section{Availability of data and materials}

All neuroimaging and neuropsychology data are available from the official ADNI website (http://adni.loni.usc.edu), after registration.

\section{Funding}

This work was supported by the National Research Foundation of Korea (NRF) grant funded by the Korea government (MSIT) (NRF-2019R1A5A2027340) and the National Research Council of Science \& Technology (NST) grant by the Korea government (MSIP) (No. CRC-15-04-KIST).

\section{Author's contributions}

SJK and SYW were responsible for data acquisition, analysis, and drafted the manuscript for intellectual content. YJK, YK, HJ, SEK, JPK, and YHJ contributed to data collection. EJK, HJK, and DLN read and approved the final version of the manuscript. SK and SWS contributed to the hypothesis, interpretation of the analysis, and revised the manuscript for intellectual content.

\section{Acknowledgements}

Data were obtained from the Alzheimer's Disease Neuroimaging Initiative (ADNI) database (http://adni.loni.usc.edu). As such, we thank the investigators within the ADNI contributed to the design and implementation of ADNI and/or provided data but did not participate in the analysis or writing of this report. We would also like to acknowledge the helpful discussions of our colleagues.

\section{References}

1. Petersen RC, Doody R, Kurz A, Mohs RC, Morris JC, Rabins PV, et al. Current concepts in mild cognitive impairment. Arch Neurol. 2001;58(12):1985-92.

2. Morris JC, Storandt M, Miller JP, McKeel DW, Price JL, Rubin EH, et al. Mild cognitive impairment represents early-stage Alzheimer disease. Arch Neurol. 2001;58(3):397-405.

3. Busse A, Hensel A, Guhne U, Angermeyer MC, Riedel-Heller SG. Mild cognitive impairment: long-term course of four clinical subtypes. Neurology. 2006;67(12):2176-85.

4. Chetelat G, Villemagne VL, Villain N, Jones G, Ellis KA, Ames D, et al. Accelerated cortical atrophy in cognitively normal elderly with high beta-amyloid deposition. Neurology. 2012;78(7):477-84.

5. Villemagne VL, Burnham S, Bourgeat P, Brown B, Ellis KA, Salvado O, et al. Amyloid beta deposition, neurodegeneration, and cognitive decline in sporadic Alzheimer's disease: a prospective cohort study. Lancet Neurol. 2013;12(4):357-67.

6. Sachdev PS, Lipnicki DM, Crawford J, Reppermund S, Kochan NA, Trollor JN, et al. Factors predicting reversion from mild cognitive impairment to normal cognitive functioning: a population-based study. PLoS One. 2013;8(3):e59649.

7. Larrieu S, Letenneur L, Orgogozo JM, Fabrigoule C, Amieva H, Le Carret N, et al. Incidence and outcome of mild cognitive impairment in a population-based prospective cohort. Neurology. 2002;59(10):1594-9. 
8. Okello A, Koivunen J, Edison P, Archer HA, Turkheimer FE, Nagren K, et al. Conversion of amyloid positive and negative $\mathrm{MCl}$ to AD over 3 years: an 11C-PIB PET study. Neurology. 2009;73(10):754-60.

9. Wolk DA, Price JC, Saxton JA, Snitz BE, James JA, Lopez OL, et al. Amyloid imaging in mild cognitive impairment subtypes. Ann Neurol. 2009;65(5):557-68.

10. Doraiswamy PM, Sperling RA, Johnson K, Reiman EM, Wong TZ, Sabbagh MN, et al. Florbetapir F 18 amyloid PET and 36month cognitive decline: a prospective multicenter study. Mol Psychiatry. 2014;19(9):1044-51.

11. Ye BS, Kim HJ, Kim YJ, Jung NY, Lee JS, Lee J, et al. Longitudinal outcomes of amyloid positive versus negative amnestic mild cognitive impairments: a three-year longitudinal study. Sci Rep. 2018;8(1):5557.

12. Buerger K, Teipel SJ, Zinkowski R, Blennow K, Arai H, Engel R, et al. CSF tau protein phosphorylated at threonine 231 correlates with cognitive decline in $\mathrm{MCl}$ subjects. Neurology. 2002;59(4):627-9.

13. Jack CR, Jr., Petersen RC, Xu YC, O'Brien PC, Smith GE, Ivnik RJ, et al. Prediction of AD with MRI-based hippocampal volume in mild cognitive impairment. Neurology. 1999;52(7):1397-403.

14. Drzezga A, Lautenschlager N, Siebner H, Riemenschneider M, Willoch F, Minoshima S, et al. Cerebral metabolic changes accompanying conversion of mild cognitive impairment into Alzheimer's disease: a PET follow-up study. Eur J Nucl Med Mol Imaging. 2003;30(8):1104-13.

15. Jack CR, Jr., Knopman DS, Jagust WJ, Petersen RC, Weiner MW, Aisen PS, et al. Tracking pathophysiological processes in Alzheimer's disease: an updated hypothetical model of dynamic biomarkers. Lancet Neurol. 2013;12(2):207-16.

16. Sona A, Ellis KA, Ames D. Rapid cognitive decline in Alzheimer's disease: a literature review. Int Rev Psychiatry. 2013;25(6):650-8.

17. DeCarli C. Mild cognitive impairment: prevalence, prognosis, aetiology, and treatment. Lancet Neurol. 2003;2(1):15-21.

18. Jang H, Park J, Woo S, Kim S, Kim HJ, Na DL, et al. Prediction of fast decline in amyloid positive mild cognitive impairment patients using multimodal biomarkers. Neuroimage Clin. 2019;24:101941.

19. Nagin DS. Group-based trajectory modeling: an overview. Ann Nutr Metab. 2014;65(2-3):205-10.

20. Nagin DS, Odgers CL. Group-based trajectory modeling in clinical research. Annu Rev Clin Psychol. 2010;6:109-38.

21. Xie H, Mayo N, Koski L. Identifying and characterizing trajectories of cognitive change in older persons with mild cognitive impairment. Dement Geriatr Cogn Disord. 2011;31(2):165-72.

22. David ND, Lin F, Porsteinsson AP, Alzheimer's Disease Neuroimaging I. Trajectories of Neuropsychiatric Symptoms and Cognitive Decline in Mild Cognitive Impairment. Am J Geriatr Psychiatry. 2016;24(1):70-80.

23. Lee JS, Cho SK, Kim HJ, Kim YJ, Park KC, Lockhart SN, et al. Prediction Models of Cognitive Trajectories in Patients with Nonamnestic Mild Cognitive Impairment. Sci Rep. 2018;8(1):10468.

24. Samtani MN, Farnum M, Lobanov V, Yang E, Raghavan N, Dibernardo A, et al. An improved model for disease progression in patients from the Alzheimer's disease neuroimaging initiative. J Clin Pharmacol. 2012;52(5):629-44.

25. Perrin RJ, Fagan AM, Holtzman DM. Multimodal techniques for diagnosis and prognosis of Alzheimer's disease. Nature. 2009;461(7266):916-22.

26. Petersen RC, Aisen PS, Beckett LA, Donohue MC, Gamst AC, Harvey DJ, et al. Alzheimer's Disease Neuroimaging Initiative (ADNI): clinical characterization. Neurology. 2010;74(3):201-9.

27. Aisen PS, Petersen RC, Donohue MC, Gamst A, Raman R, Thomas RG, et al. Clinical Core of the Alzheimer's Disease Neuroimaging Initiative: progress and plans. Alzheimers Dement. 2010;6(3):239-46.

28. Landau SM, Mintun MA, Joshi AD, Koeppe RA, Petersen RC, Aisen PS, et al. Amyloid deposition, hypometabolism, and longitudinal cognitive decline. Ann Neurol. 2012;72(4):578-86.

29. Landau SM, Lu M, Joshi AD, Pontecorvo M, Mintun MA, Trojanowski JQ, et al. Comparing positron emission tomography imaging and cerebrospinal fluid measurements of beta-amyloid. Ann Neurol. 2013;74(6):826-36.

30. Mohs RC, Knopman D, Petersen RC, Ferris SH, Ernesto C, Grundman M, et al. Development of cognitive instruments for use in clinical trials of antidementia drugs: additions to the Alzheimer's Disease Assessment Scale that broaden its scope. The 
Alzheimer's Disease Cooperative Study. Alzheimer Dis Assoc Disord. 1997;11 Suppl 2:S13-21.

31. Jagust WJ, Landau SM, Shaw LM, Trojanowski JQ, Koeppe RA, Reiman EM, et al. Relationships between biomarkers in aging and dementia. Neurology. 2009;73(15):1193-9.

32. Jack CR, Jr., Bernstein MA, Fox NC, Thompson P, Alexander G, Harvey D, et al. The Alzheimer's Disease Neuroimaging Initiative (ADNI): MRI methods. J Magn Reson Imaging. 2008;27(4):685-91.

33. Lo RY, Hubbard AE, Shaw LM, Trojanowski JQ, Petersen RC, Aisen PS, et al. Longitudinal change of biomarkers in cognitive decline. Arch Neurol. 2011;68(10):1257-66.

34. Nagin DS, Tremblay RE. What has been learned from group-based trajectory modeling? Examples from physical aggression and other problem behaviors. The Annals of the American Academy of Political and Social Science. 2005;602(1):82-117.

35. Ferro MA, Speechley KN. Stability of latent classes in group-based trajectory modeling of depressive symptoms in mothers of children with epilepsy: an internal validation study using a bootstrapping procedure. Soc Psychiatry Psychiatr Epidemiol. 2013;48(7):1077-86.

36. Nagin DS, NAGIN D. Group-based modeling of development: Harvard University Press; 2005.

37. Efron B, Tibshirani R. Bootstrap methods for standard errors, confidence intervals, and other measures of statistical accuracy. Statistical science. 1986:54-75.

38. Kryscio RJ, Schmitt FA, Salazar JC, Mendiondo MS, Markesbery WR. Risk factors for transitions from normal to mild cognitive impairment and dementia. Neurology. 2006;66(6):828-32.

39. Hand DJ, Till RJ. A simple generalisation of the area under the ROC curve for multiple class classification problems. Machine learning. 2001;45(2):171-86.

40. Van Calster B, Van Belle V, Vergouwe Y, Timmerman D, Van Huffel S, Steyerberg EW. Extending the c-statistic to nominal polytomous outcomes: the Polytomous Discrimination Index. Stat Med. 2012;31(23):2610-26.

41. Jones BL, Nagin DS, Roeder K. A SAS procedure based on mixture models for estimating developmental trajectories. Sociological methods \& research. 2001;29(3):374-93.

42. Jones DJ, Runyan DK, Lewis T, Litrownik AJ, Black MM, Wiley T, et al. Trajectories of childhood sexual abuse and early adolescent HIV/AIDS risk behaviors: the role of other maltreatment, witnessed violence, and child gender. J Clin Child Adolesc Psychol. 2010;39(5):667-80.

43. Kim YJ, Cho SK, Kim HJ, Lee JS, Lee J, Jang YK, et al. Data-driven prognostic features of cognitive trajectories in patients with amnestic mild cognitive impairments. Alzheimers Res Ther. 2019;11(1):10.

44. Bhagwat N, Viviano JD, Voineskos AN, Chakravarty MM, Alzheimer's Disease Neuroimaging I. Modeling and prediction of clinical symptom trajectories in Alzheimer's disease using longitudinal data. PLoS Comput Biol. 2018;14(9):e1006376.

45. Hochstetler H, Trzepacz PT, Wang S, Yu P, Case M, Henley DB, et al. Empirically Defining Trajectories of Late-Life Cognitive and Functional Decline. J Alzheimers Dis. 2016;50(1):271-82.

46. Wang Y, Haaksma ML, Ramakers I, Verhey FRJ, van de Flier WM, Scheltens P, et al. Cognitive and functional progression of dementia in two longitudinal studies. Int J Geriatr Psychiatry. 2019;34(11):1623-32.

47. Leoutsakos JM, Forrester SN, Corcoran CD, Norton MC, Rabins PV, Steinberg MI, et al. Latent classes of course in Alzheimer's disease and predictors: the Cache County Dementia Progression Study. Int J Geriatr Psychiatry. 2015;30(8):824-32.

48. Wilkosz PA, Seltman HJ, Devlin B, Weamer EA, Lopez OL, DeKosky ST, et al. Trajectories of cognitive decline in Alzheimer's disease. Int Psychogeriatr. 2010;22(2):281-90.

49. van Rossum IA, Visser PJ, Knol DL, van der Flier WM, Teunissen CE, Barkhof F, et al. Injury markers but not amyloid markers are associated with rapid progression from mild cognitive impairment to dementia in Alzheimer's disease. $J$ Alzheimers Dis. 2012;29(2):319-27.

50. Snider BJ, Fagan AM, Roe C, Shah AR, Grant EA, Xiong C, et al. Cerebrospinal fluid biomarkers and rate of cognitive decline in very mild dementia of the Alzheimer type. Arch Neurol. 2009;66(5):638-45. 
51. Liu CC, Liu CC, Kanekiyo T, Xu H, Bu G. Apolipoprotein E and Alzheimer disease: risk, mechanisms and therapy. Nat Rev Neurol. 2013;9(2):106-18.

\section{Figures}

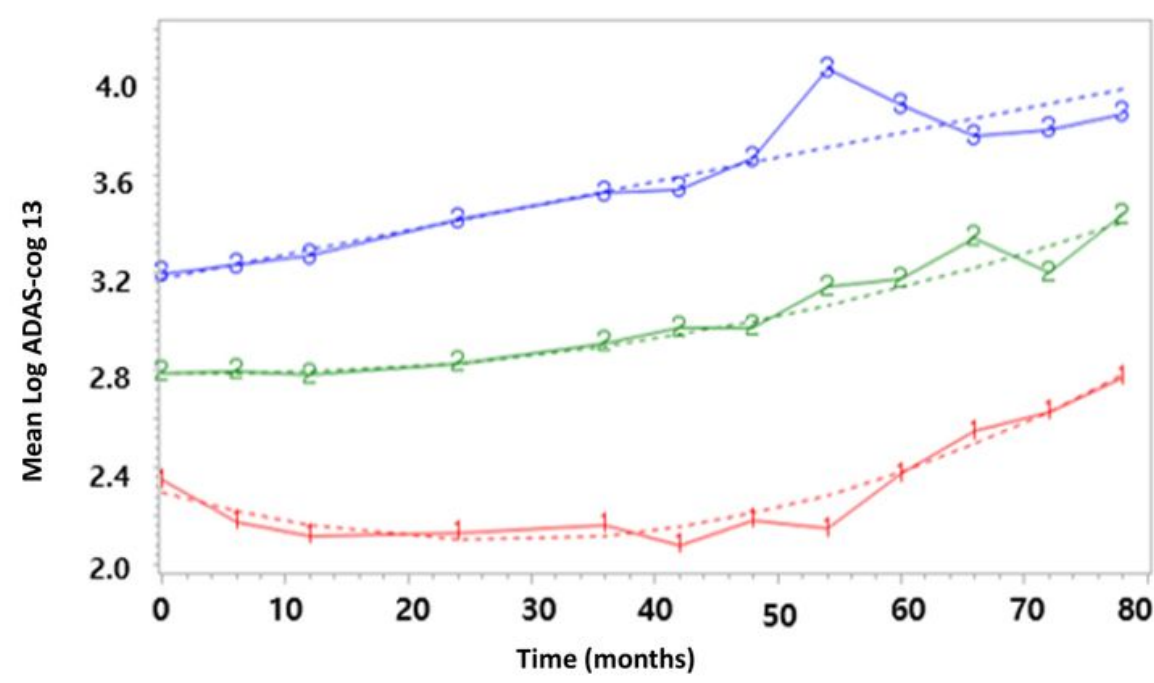

$\leftrightarrow$ Group 1: slow decliners, $n=44(18.5 \%)$

Group 2: intermediate decliners, $n=102(42.9 \%)$

$\leftrightarrow$ Group 3: fast decliners, $n=92(38.7 \%)$

Time (months)

\section{Figure 1}

Classified cognitive longitudinal trajectories: group-based trajectory model analysis based on ADAS-cog 13 score over time Abbreviations: Log ADAS-cog, Log transformed the Alzheimer's Disease Assessment Scale-cognitive subscale The y-axis represents the natural log-transformed (ADAS-cog 13). Three trajectory groups were identified: slow decliners; intermediate decliner; fast decliner. Solid lines depict mean of observed trajectories and dashed lines depict estimated trajectories for each group.

A

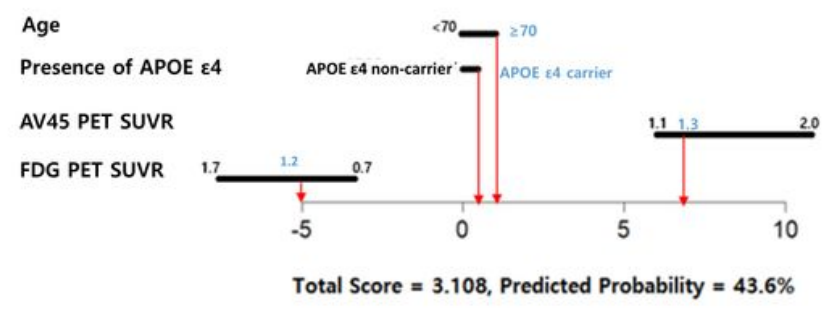

B

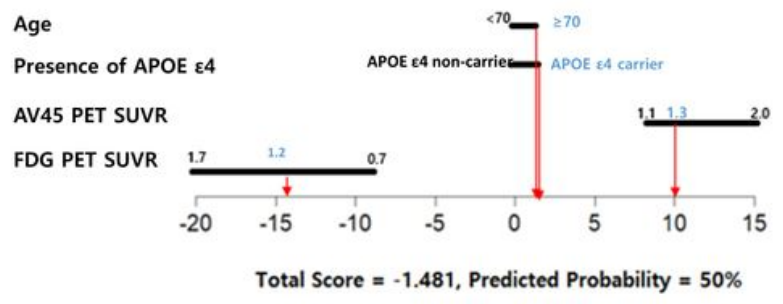

Figure 2

Graphical representation of the model of predictors The exemplary case is a patient with 75 years, APOE4 carrier, AV45 SUVR 1.3, and FDG SUVR 1.2. (A) Total score and predicted probability regarding intermediate decliner (B) Total score and predicted probability regarding fast decliner. The black lines indicate the range of risk score for each predictor as observed in the data set. The red arrows indicate the predictors' risk scores to the linear predictor for this specific patient. The specific predictor 
values given a specific patient are indicated in blue color. The total score at the bottom of the graph is the sum of all predictor risk scores. The predicted probability corresponding to this total score is given as well. (A) indicates total score for intermediate decliner group comparing to slow decliner group and predicted probability being intermediate decliner. The total score made from the sum of each score is 3.108 . The predicted probability corresponding to this total score is $43.6 \%$. (B) indicates total score for fast decliner group comparing to slow decliner group and predicted probability being fast decliner. The total score made from the sum of each score is -1.481 . The predicted probability corresponding to this total score is $50 \%$. The predicted probability for slow decliner is $6.4 \%(=100 \%-(43.6 \%+50 \%))$. 